\title{
CONCEPTUAL OR EXPERIENCE-BASED LEARNING OF TEACHERS*
}

\author{
H. H. TILLEMA, R. DE JONG, and CH. MATHIJSSEN \\ University of Groningen, The Netherlands
}

\begin{abstract}
This paper presents the results of a field experiment. in which a variation in the didactical arrangement of a training course for teachers was investigated. It was hypothesized that a conceptually oriented training program, consisting of certain training components, would benefit teachers most. The theoretical background of the hypothesis is discussed. The impact of the variation on teachers' knowledge, perception of competence and performance was assessed. The results show clear support for the hypothesis on measures related to knowledge and perception of competence, but not on those related to performance or actual competence.
\end{abstract}

Recently the quality of teaching has become a major theme in the training and education of teachers. Also a new interest has developed in methods for achieving concrete and observable changes in the teacher's behavioral repertoire. Conceptions of training (Grell, 1978; Tillema \& Veenman, 1987) have long been dominated by a behavioristic and skill-oriented interpretation of teacher competencies, with a stress on elementary behaviors and training of the observable components of behavioral repertoires. In the heyday of this approach there was typically a concern for (a) development of training as a set of interventions (e.g., microteaching), (b) comparisons with other treatment packages, and (c) a criterion defined as change in predetermined behaviors.

Training research showed that teacher behavior can be changed in a more or less consistent way. However, the contribution of training was mainly of a piecemeal nature. Effective methods in achieving observable change in parts of the behavioral repertoire did not result in "orchestrated" behaviors for more complex settings (Fenstermacher, 1981). For some time it has been apparent (Guskey, 1986; Tillema \& Veenman, 1987) that, because of a lack of theoretical background and practical relevance, interest in training as a means of achieving mastery in teaching repertoires has diminished. Other aims, such as attitude-change and knowledge dissemination or innovative roles for teachers (OECD, 1981), have had negative effect on the importance of achieving competence through training of behaviors. Because of this, even the more effective training methods, such as microteaching (MacLeod, 1987), have been used significantly less often.

More recent developments in training have largely been influenced by a shift toward cognitive orientations in education (Norman, 1980). This shift has had the following effects:

1. A greater validity of the training with respect to the mastery of competencies. It is no longer widely thought to be true that competencies can be broken down into elementary skills that can be learned separately.

2 . The recognition that prior knowledge and teacher cognitions or beliefs influence their execution of competencies. Behavioral skills are part of a repertoire in which teachers not only execute skills but also judge, make decisions, and process information.

3. More differentiated design of training. No longer is training regarded as a fixed treatment, it is rather regarded as a learning program for

* This research has been made possible thanks to a subsidy granted by SVO-Institute for Educational Research in the Netherlands (SVO-project 6622). 
the teacher. Cognitive processes, that can be steered through a specific combination of training components, are stressed (Cruickshank \& Haefele, 1987; Gliessman \& Pugh, 1984; Joslin. 1980; Joyce \& Showers, 1980; Stallings, 1985; Zeichner, 1987).

In recent studies of training we see an interest in dealing with at least the following two problems, which are addressed in the present study:

1. Which combination of training components is most effective for fostering the learning of teaching competencies?

2 . In which way can teacher cognition be reconciled with the training of competencies?

\section{Training Components}

Based mainly on the work of Joyce and Showers and of Stallings, several training components have been identified. In a certain combination, these components form a specific training method. These components take such forms as protocol materials, reflective training, and microteaching (Joslin, 1980; Sparks, 1983; Wade, 1984).

Using the work of Stallings, we can distinguish the following components:

1. Diagnosis: Establishing the prior knowledge and beliefs of teachers before training is delivered is important for ascertaining which teacher orientations and perspectives will structure the content of the training. Prior incidental learning, misconceptions perhaps, can influence the reception of the materials and skills to be learned. Guskey (1986) recognized this component as important for developing awareness of, and forming attitudes towards, the competency.

2. Instruction and demonstration: The shift toward concern with cognitions is most apparent within this component. Whereas the behavioristic approach stressed practice, more recent conceptualizations of training stress the acquisition and processing of relevant information, especially the conceptual foundation of the competencies to be learned (Gliessman, 1983). The manner in which this acquisition and processing are fostered differs in the specific training methods. For instance, protocol materials (Cruickshank \& Haefele, 1987) focus on the conceptualization of demonstrations. Reflective training (Zeichner, 1987) focuses on own experiences and conceptual reflection on and discussion of one's own behavior. Conceptual training (Gliessman \& Pugh, 1987) focuses on concept attainment and cognitive differentia. tion with respect to the skill to be learned.

3. Application and discussion: This training component has changed from a practice-anddrill interpretation to a (differentiated) exchange of experiences and a practising of what has been learned previously. Under the influence of implementation studies (e.g. . Berman \& McLaughlin, 1977) and training studies (e.g., Good, Grouws, \& Ebmeier, 1983), it has been recognized that individual practice without external support (through materials, proper settings, and corrective feedback from peers) is too limited. Teachers themselves (Holly, 1982) find practice. together with help in the form of materials of counseling, the most stimulating and interesting part of the training. Time for discussion and exchange of experiences has also proved to be an effective part of training (Evertson, Emmer, Sanford, \& Clements. 1983). Sparks (1983) found that the amount of training can be lessened if exchange of experiences is used instead of practising with a trainer.

4. Coaching: Follow-up after training has proved to be a valuable extension of the laboratory-training model. Guidance and support of teachers in the protocol situation has proven to increase training and implementation of the behavioral repertoire (Huberman, 1985). Training is most often confined to out-of-school situations, and coaching brings these two spheres, the training and school settings, together. Joyce and Showers (1982) suggested that coaching is more effective when delivered to teams of teachers who are already cooperating. Sparks (1983) found that intensity of coaching is a crucial variable. Implementation studies (Fullan. 1983) have pointed to the importance of regular exchange of experiences with the training content between colleagues and in interaction with the trainer.

As is apparent from most training studies, almost every training program consists of a certain blend of all of the aforementioned training components, hardly ever explicitly excluding a certain component.

\section{Acquisition of Competence}

A number of studies (Joslin, 1980; Wade, 1984; Walberg \& Genova, 1982) have been di- 
rected toward determining the relative impact of training arrangements (self practice, lecturing, the reading of materials). These studies show that in training practice, the "tell and do" tradition is still strong. They also show that greater effect sizes are achieved by training methods which (a) use exchange of information through discussion between peers, and (b) are based on direct conceptual instruction by the trainer. The question of how competencies are best acquired refers exactly to these two conceptualizations of training.

The most frequently used approach is direct instruction by a trainer. Transfer of knowledge by giving instruction and telling or demonstrating how to perform is the major vehicle in the history of teacher training. Another approach, however, is just as old: experience, discovery, and learning by doing. In the training literature we see these two conceptualizations evolve into two different kinds of training approaches which rarely meet. Both conceptualizations have a profound influence on the design of training and the training components which are being stressed. For instance, the component of instruction is most often presented theoretically and in elaborated lectures in the conceptual approach, whereas in a more experiential approach it can consist of activation of prior experiences and the use of ideas from peers as a basis for learning. Practice in the conceptual approach is often trainer-led, whereas in the experiential approach it consists of discussion (talking through instead of acting through).

The results of implementation studies (Crandall, 1984; Walberg \& Genova, 1982) seem to indicate that training which focuses on selflearning and exchange with peers about experiences has a greater impact and yields higher effect sizes than the more conceptual training approaches with their attention to instruction and conceptual information. On the other hand, more recent training studies indicate the importance of conceptual instruction as a basis for acquiring competencies (Brophy \& Good, 1986).

Conceptually oriented approaches to training start from the premise that development of competency is based on the attainment of clear and structured concepts or ideas about a competency. As a competency is being executed, it is associated with a weighing of alternatives, decision making, comparison of behavioral effects
- in a word, with cognitions. Therefore, the acquiring of competencies is regarded as a cognitive process. The learning of the essential and meaningful concepts is a matter of training. If the concepts have been acquired, it is not even crucial whether the competency is actually being put into practice. Only the acquisition and processing of the conceptual information are central. Results of experiments by Gliessman and Pugh (1987) and MacLeod (1987) clearly showed the effectiveness of direct, conceptual instruction, although no direct comparison was made with more experiential approaches.

However, we found other results not so much in training studies as in implementation studies, which use training as a form of inservice education. In some studies (Berman \& MacLaughlin, 1978; Crandall \& Huberman, 1982; Fullan, 1982), we find a substantial effect for exchange of experiences. Implementation studies also focus on achieving relatively permanent behavioral changes in teachers as a consequence of training (as well as other factors). From these studies one could learn that self study, that is, learning with materials, together with subsequent exchange of experiences through discussion with peers (learning from each other), has major effects even compared with more instruction-like approaches, such as lecturing. The claim is that colleagues, better than trainers, can tell what works, know better in what situation transfer is feasible and are far ahead in detecting problems in executing the behaviors.

Through exchanging ideas teachers transform the 'theoretical' competencies faster into daily action (Lortie, 1975). It is claimed that fewer transfer problems arise within an experiential approach than within a conceptual approach.

The exchange of ideas has several functions: exploring what is to be acquired, providing corrective feedback on the performance, and sharpening judgements about practicality. A trainer in this approach has the function of facilitator and enhancer of relevant information.

The goal of our study was to compare these two training approaches, as embodied in specific elaborations of the different training components.

The research questions were:

- Does training designed on the basis of a conceptual approach have a different effect on 
amount of new learning and amount of perceived or actual mastery of the competency than training designed on an experiential basis; and do both kinds of training have different effects from those of a regular or standard training?

- Does variation in the amount of elaboration of the instruction component as compared with the practice component facilitate or inhibit the effects of either the conceptual or the experiential approach on amount of new learning, and amount of perceived or actual mastery?

\section{Design}

\section{Setting}

In a field experiment, 156 polytechnic teachers in secondary education participated in a training course. The content of the training course consisted of five successive sessions of 3 to 4 hours each, on learning competencies with respect to thematic education within the content area of general technology education. In the training sessions, the teachers were acquainted, according to one of the conditions, with skills regarding drawing up a lesson plan fitting the criteria of thematic education (e.g., rearranging or making textbook material, finding suitable topics for a series of lessons. construing pupil assignments, drawing up an evaluation plan). Teachers could voluntarily subscribe to one of the seven training sites.

\section{Procedure}

Prior to the training the teacher trainers were instructed about the aims and requirements of the experiment: six conditions were to be established in which the trainers (with the help of materials and instruction by the research team) arranged each of the sessions in such a way that they would form one of the six treatments. A seventh group would form the control condition. The trainers were acquainted with the materials and tests to be used during instruction.

\section{Conditions}

Trainers were allocated to one of the seven conditions based on observation of a prior training session. Using a rating system that was also used in the experiment for control of adequate implementation of the treatment, the inves- tigators (the authors) rated each trainer as to his or her match with one of the conditions. The operational differences measured between the conditions were:

1. Amount of instruction time: measured by the amount of trainer's verbal action (conceptual-high; experiential-low).

2. Amount of interaction between trainer/ group of trainees (conceptual-high: experiential-low).

3. Number of trainee-initiated responses (conceptual-low; experiential-high).

4. Length of time for individual assignments and practice (conceptual-high; experientiallow).

Video recording and rating of a number of sessions in every condition resulted in an interrater reliability of .62 (Cohen's Kappa).

The conditions shown in Table 1 were established.

After the allocation of each trainer to a treatment, the trainers were given materials and received an instruction on the arrangement of the training sessions. Three foci (Instruction, Practical, and Mixed) were crossed with two training approaches (Conceptual and Experiential) to form the six experimental treatments, along with the seventh, or control, treatment. An overview of the seven treatments follows:

Conceptual-Instructional (CI)

The trainer is an instructor, giving clear information about concepts concerning thematic lesson arrangements with little opportunity for practice except in the form of assignments.

Conceptual-Practice (CP):

The trainer is an instructor giving only essential information and giving plenty of time to work out problems (with the trainees).

Conceptual-Mixed (CM):

The trainer is an instructor who spends equal time on lecturing and problem solving.

Experiential-Instructional (EI)

The trainer is a facilitator in the group of trainees which is invited to exchange and discuss ideas and solutions.

Experiential-Practice (EP):

The trainer is a facilitator in which small groups work out problems on the basis of their own ideas.

Experiential-Mixed (EM):

As in CM, equal time is given to discussion and problem solution.

Control (con):

Three control training sites were included, in these the trainer was invited to follow the regular program consisting of a blend of all training components. 
Table 1

\begin{tabular}{|c|c|c|c|}
\hline & \multicolumn{3}{|c|}{ Training approach } \\
\hline & & $\begin{array}{c}\text { Conceptual } \\
\text { (C) }\end{array}$ & $\begin{array}{l}\text { Experiential } \\
\text { (E) }\end{array}$ \\
\hline & $\begin{array}{l}\text { Instruction } \\
\text { (I) }\end{array}$ & $\begin{array}{r}\text { CI } \\
n=21 \\
\end{array}$ & $\begin{array}{r}\text { EI } \\
n=12 \\
\end{array}$ \\
\hline Focus & $\begin{array}{r}\text { Practice } \\
\text { (P) }\end{array}$ & $n=\begin{array}{l}\text { CP } \\
24\end{array}$ & $n=\begin{array}{l}\mathrm{EP} \\
n=10\end{array}$ \\
\hline & $\begin{array}{l}\text { Mixed } \\
\text { (M) }\end{array}$ & $\begin{array}{rl} & \mathrm{CM} \\
n=16 & 16\end{array}$ & $\begin{aligned} & \text { EM } \\
& n=10\end{aligned}$ \\
\hline & Control & & \\
\hline
\end{tabular}

\section{Observation}

During the training sessions an observable instrument was used to ascertain the correctness of the implementation of the training condition in the actual training. The validity of the experiment could of course be damaged if the trainer did not perform according to the selected condition. A time rating system was developed: every 10 seconds the investigator rated the total amount of instruction time divided into (a) instruction by trainer, (b) working in groups, (c) discussion, and (d) organizational time (not relevant time) as one of the indicators of the conditions. The other indicators were frequency ratings: (a) amount of interactions between trainer and group, (b) number of trainee initiated responses, (c) length of practice time. Based on the total amount of scoring in a category a condition was identified and labeled as a specific treatment. The statistical analyses were performed on the treatment as identified by the observation system.

\section{Measurement}

The field experiment consisted of a pretestposttest control group design. The pretest was taken some weeks before the training. It consisted of (a) an entry test consisting of a questionnaire measuring characteristics of the trainees, with items on educational background, experience in subject matter, and expectations of using the course for one's own practice. Because the treatment groups are not randomized or matched, these measurements were to be used as a control for relevant differences between groups-covariables; (b) a prior knowledge test measuring the knowledge of the trainees about arranging thematic instruction (16 multiple choice items, derived from the course book used by the trainers, about content selection, making assignments, and subject matter content).

The posttest consisted of (a) a learning test, containing 12 items measuring the knowledge gained from the course about thematic education. The test items were derived from the stated goals of the course as agreed upon by the trainers, for example, what classroom-materials are pupils to use to make an electrical questiongame (with alpha $=.60 ;$ mean $=5.7 ; p$-value $=.59$ ); (b) an application test, consisting of 11 items in which trainees had to solve a problem resembling the ones that were dealt with in the sessions, for example, derive carpentry assignments for the lesson topic 'rearranging your room' (the correctness of the solution was established by the trainer; reliability: alpha $=$ $.84)$; (c) a learner report: 11 items on specified topics in which the trainee idicated what he/she had gained from the course, for example, "I am able to write higher cognitive questions for topic ..." (homogeneity alpha $=.83$, mean $=2.3$ on a Likert scale), and (d) a mastery test: an assignment to plan a lesson according to the principles learned; to be rated by the trainer of the session (e.g., a detailed step plan for a lesson topic including motivational entry, focus of the lesson, selection criteria, materials to be used in a les- 
son; homogeneity alpha $=.78$, mean rating by trainer was 6.9 on a 10 point scale).

\section{Results}

A first analysis established which trainee characteristics were correlated with the dependent variables and had to be included as covariates. It showed that only prior knowledge and expectation of utilization had significant correlations (Spearman $r=.48$ and .18 respectively) with the learning test. Experience in the subject matter had a significant correlation only with the learner report $(r=-.21)$ and the mastery test $(r=.24)$. These variables were subsequently used as covariates in further analyses.

Table 2 shows the means and standard deviations of the dependent variables for each of the seven treatments.

No differences were found on the present between treatment-groups in the training.

Analysis of covariance (MANCOVA) revealed significant differences between treatment-group mean scores in favor of the conceptual conditions both on the learning test $\left(F_{5.69}=\right.$ 4.22:p<.002), and on the learner report $\left(F_{5.69}\right.$ $=5.54 ; p<.000$ ) (both tests were of knowledge). No significant differences were found on the application test $\left(F_{3.62}=2.42 ; p<.07\right)$ and mastery tests $\left(F_{3.34}=0.51 ; p<.95\right.$ (both tests dealt with performance). The covariates taken together explained $17 \%$ of the between group variance; prior knowledge alone explained $10 \%$ of the between group variance. The difference between treatments explained $13 \%$ of the between group variance on the learning test, and $5 \%$ of that on the learner report. Separate analyses of covariance were done on the effects of the training approach (conceptual or experiential) and training components. It showed that the difference between the conceptual and experiential approach was significant on the posttest $\left(F_{1.62}=11.47: p<.001\right)$. No difference was found on this test between the training components $\left(F_{2.62}=.68 ; p<.51\right)$. The interaction effect between approach and components reached significance $\left(F_{2.69}=3.27: p<.04\right)$ favoring a conceptual approach with instruction components in contrast to an experiential approach with discussion components. With respect to the learner report, the effects of both approach and components reached significance $\left(F_{1.65}=4.31 ; p<.04\right.$ and $\left(F_{2.65}=3.32 ; p<.042\right.$, respectively). The interaction between both was significant $\left(F_{2.65}=4.29 ; p<.018\right)$, also favoring a conceptual and practice approach above an instruction-like, experiential approach. On the mastery test no significant differences were found.

\section{Discussion}

An experiment was designed to determine the effects of variation in training courses with respect to (a) conceptual or experiential instruction and (b) amount of time devoted to knowledge transfer or instruction and practice. Effects of variation in the treatments were measured on new learning, application of knowledge, perception of knowledge gained, and mastery of the competencies trained. The questions to be investigated were:

- Does conceptual instruction lead to more learning and mastery of a competency than experiential instruction?

- Does training with a greater amount of time devoted

Table 2

Means and Standard Deviations of the Dependent Variables for each Treatment

\begin{tabular}{|c|c|c|c|c|c|c|c|c|}
\hline \multirow[b]{2}{*}{ Treatment } & \multicolumn{2}{|c|}{$\begin{array}{c}\text { Learning } \\
\text { test }\end{array}$} & \multicolumn{2}{|c|}{ Application } & \multicolumn{2}{|c|}{$\begin{array}{c}\text { Learner } \\
\text { report }\end{array}$} & \multicolumn{2}{|c|}{$\begin{array}{c}\text { Mastery } \\
\text { test }\end{array}$} \\
\hline & $M$ & $S D$ & $M$ & $S D$ & $M$ & $S D$ & $M$ & $S D$ \\
\hline Conceptual/instruction & 6.38 & 1.40 & .63 & .84 & 5.98 & 1.76 & 6.98 & 1.67 \\
\hline Conceptual/practice & 4.60 & 1.85 & .41 & .91 & 6.66 & 1.38 & 4.91 & 1.95 \\
\hline Conceptual/mixed & 5.97 & 2.35 & .24 & 41 & 6.87 & 1.71 & 6.14 & 1.68 \\
\hline Experiential/instruction & 5.43 & 1.84 & .05 & .04 & 4.34 & 1.75 & 5.47 & 1.81 \\
\hline Experiential/practice & 6.46 & 2.39 & .83 & 1.00 & 4.71 & 1.77 & 7.13 & 2.73 \\
\hline Experiential/mixed & 3.61 & 1.57 & .20 & .49 & 4.44 & 2.18 & 3.86 & 1.59 \\
\hline Control & 4.88 & 2.28 & .47 & .70 & 5.85 & 1.27 & 6.25 & 1.91 \\
\hline
\end{tabular}


devoted to instruction than to practice lead to more learning and mastery of a competency?

Influencing factors, namely, prior knowledge and amount of experience of the teachers, were controlled with analyses of covariance.

A clear and substantial difference was found with respect to what the teachers think they have learned from the course (also including their attitude towards the content of the training). Conceptual instruction had a positive effect and outperformed an experiential approach. There was an interaction with training components. It was found that time devoted to (trainer instructed) practice was thought to be more effective than (and favored above) lecturing and discussion.

This result is to some extent surprising because the claim of experiential instruction has been that it is better suited to education of adults (such as teachers) than conceptual instruction. This experiment shows that teachers favored a direct approach in learning concepts, although in such a learning process most time has to be devoted to practice (under the guidance of a trainer expert).

The treatments also affected the knowledge gained from the training, although a distinction has to be made between "knowing that" and "knowing how". A clear difference was found in the amount of new learning as a result of the treatment; conceptual instruction outperformed experientially based instruction.

No effect was found for the differences in the training components (either more time devoted to instruction or to practice). However, an interesting interaction effect appeared: contrary to what was expected, the experiential-practice-oriented treatment outperformed the other conditions in absolute terms. The next best treatment was the conceptual-instructionoriented treatment. This could mean that the more clearly conceptualized training methods do better than mixed forms containing elements of different approaches. Another relevant finding is that no effects of the treatments could be established on the performance tests (application and mastery tests) as against the knowledge tests (learning test and learner report). The training conditions did not result in different attainment of competence.

When the results of this experiment are confronted with recent conceptualizations of train- ing of teachers, support is found for the conceptual approach in training (Gliessman \& Pugh, 1987; Katz \& Rath, 1983; MacLeod, 1987) which stresses the clear presentation of central concepts as a basis for interpretation and reflection on performance. But it is not altogether true that conceptual training can be equated with direct and trainer-led instruction, because results on the perception measurements indicate that the to-be-learned concepts need to be worked out in practice sessions which give room for the enactment and elaboration of concepts. This experiment gives no conclusive results concerning the experiential approach, although it performed significantly less well than conceptual training. A strictly experiential approach, building on the ideas of teachers and exchanging them with colleagues, yielded high effect scores. Contrary to what was expected, variations in training components per se had no major influence on the outcomes of training. Training components may be more effective depending on how they are combined with a training approach. Clearly, differentiation between components as a basis for distinguishing between training methods could not be supported by the results of this experiment.

The conclusions indicate that, in the conceptualization of training, the precise interrelation between knowledge acquisition and performance may be overlooked. This familiar problem in the training literature underscores again the idea that 'knowing that' is not a sufficient condition for 'knowing how' (Walberg, 1984; Peterson, 1988). Reframing this problem, we can say that, through teacher thinking, a rapprochement between knowledge about performance and the actual performance itself could be established. In this study it was found that teachers favor training situations in which they can gain experience with the competencies but that they learn most from clear conceptual knowledge about the competency. Through establishing training situations in which teachers themselves are able to form cognitions about their performance, a better mastery of the competency might be achieved.

\section{References}

Berman, P., \& McLaughlin, M. W. (1977). Federal 
programs supporting educational change. Vol. III. Factors affecting implementation and continuation. Rand Corporation.

Brophy, J. E., \& Good, T. L. (1986). Teacher behavior and student achievement. In M. C. Wittrock (Ed.) Handbook of Research on Teaching (3rd ed., pp. 328-375). New York: Macmillan.

Crandalt, D. P., \& Huberman, A. M. (1982). People, policies, and practices examining the chain of school improvement. Andover: The Network.

Cruickshank, D. R., \& Haefele, D. (1987). Teacher preparation via protocol materials. International Journal of Educational Research, 11,543-554.

Evertson, C. M., Emmer, E. T., Sanford, J. P., \& Clements, B.S. (1983). Improving classroom management: An experiment in elementary school classrooms. Elementary School Journal, 84. 173-188.

Fenstermacher, G. D. (1981). On learning to teach effectively from research on teacher effectiveness. In $C$. Denham \& A. Lieberman (Eds.), Time to learn. Washington: National Institute of Education.

Fullan, M. (1982). The meaning of educational change. New York: Teachers College Press.

Gliessman, D. M. (1983). Changing teaching performance. In L. G. Katz \& J. D. Raths (Eds.), Advances in teacher education, vol. I. New Jersey: Ablex Publishing Corporation.

Gliessman, D. H., \& Pugh, R. C. (198t). Conceptual variables in teacher training. Journal of Education for Teaching, 10, 195-208.

Gliessman, D. H., \& Pugh, R. C. (1987). Conceptual instruction and intervention as methods of acquiring teaching skills. International Journal of Educational Research, 11, 555-563.

Good, T. L., Grouws, D. A., \& Ebmeier. H. (1983). Active mathematics teaching. New York: Longman.

Grell, J. (1978). Training van onderwijsgedrag (Training of teaching behavior). Groningen: Wolters-Noordhoff.

Guskey, T. R. (1986). Staff development and the process of teacher change. Educational Researcher, 15(5), 5-12.

Holly, F. (1982). Teachers' view on inservice training. Phi Delta Kappan, February, 417-418.

Huberman, M. (1985). What knowledge is of most worth to teachers: A knowledge use perspective. Teaching and Teacher Education, 1, 251-262.
Joslin, P. A. (1980). Inservice teacher education. A metaanalysis of the research. Unpubiished doctoral dissertation, University of Minnesota.

Joyce, B. R. \& Showers, B. (1980). Improving inservice training. The messages of research. Educational Leadership. 37. 379-385.

Lortie. D. C. (1975). Schoolteacher: A sociological study. Chicago: University of Chicago Press.

MacLeod, G. R. (1987). Micro-teaching: End of a research era. International Journal of Educational Research, 5 , $531-541$.

Norman, D. A. (1980). Cognitive engineering and education. In D. T. Tuma \& F. Reif (Eds.), Problem solving and education. New Jersey: Lawrence Erlbaum.

Organisation for Economic and Cultural Development, (1981). Inservice education and training of teachers and educational change. Paris: Organisation for Economic and Cultural Development.

Peterson, P. L. (1988). Teachers' and students' cognitional knowledge for classroom teaching and learning. Educational Researcher, 17, 5-14.

Sparks, G. M. (1983). Inservice education: Training activities, teacher atritudes, and behavior change. Unpublished doctoral dissertation. Stanford University.

Stallings, J. (1985). A mastery approach to staff development. Nashville. TN: Vanderbilt University, Peabody Center for Etfective Teaching.

Tillema. H. H., \& Veenman, S. (1987). Developments in training methods for teacher education. International Journal of Educational Research, 11, 515-599.

Wade. R. K. (1984). What makes a difference in inservice teacher education. A meta-analysis of the research. Unpublished doctoral dissertation. University of Massachusetts.

Walberg, H. J. (1984). Improving the productivity of America's schools. Educational Leadership, 41, 19-27.

Walberg. H. J., \& Genova, W. J. (1982). Staff. school, and workshop influences on knowledge. Journal of Educational Research, 76, 69-80.

Zeichner, K. M. (1987). Preparing reflective teachers. An overview of instructional strategies which have been employed in pre-service teacher education. International Journal of Educational Research, 11, 565-575.

Received 25 August 1989 